\title{
The Reaction of Solid Iron with Molten Tin*
}

\author{
By Tsuneo Ishida**
}

\begin{abstract}
A fundamental study of iron soldering has been made of the reaction of solid iron with molten tin from the viewpoints of dissolution kinetics and metallography. Small iron cylinders were immersed in molten tin in the temperature range from 445 to $780^{\circ} \mathrm{C}$ for 10 to $160 \mathrm{~min}$ under a static condition utilizing the soldering flux. The obtained values of initial dissolution-rate constant of solid Fe into molten $\mathrm{Sn}$ are $3.37 \times 10^{-4} \sim 1.12 \times 10^{-3} \mathrm{~cm} / \mathrm{sec}$ and the activation energy for dissolution depends on the temperature. Owing to the formation of intermetallic compound in solid-liquid interface, the dissolution behaviour in the high-temperature range above $496^{\circ} \mathrm{C}$ differs from that in the low-temperature range below $496^{\circ} \mathrm{C}$. The intermetallic compound formation does not appear to act as a dissolution barrier. In the high-temperature range, the dissolution process is controlled by diffusion in the boundary layer of molten metal. In the low-temperature range, the process is controlled by the formation of an intermetallic compound at the early reaction time, but a transition of reaction control of the alloy layer and molten metal occurs with time. The dissolution of solid iron into molten tin proceeds with an intensive reaction between molten tin and the alloy layer in relatively rapid growth.
\end{abstract}

(Received May 4, 1972)

\section{Introduction}

It has been well known that various reactions occur $^{(1) \sim(5)}$ when iron or iron-alloy is exposed to molten solder. However quantitative investigations on the progress of the reaction are few in numbers. In brazing and soldering it is most important to clarify the reaction mechanism of solid metal with a liquid metal. A basic study of the iron brazing has already been reported for the dissolution and the migration between solid metal and molten metal ${ }^{(6)(7)}$. The purpose of the present work is to relate the reaction of solid iron with molten tin in iron soldering.

The most striking characteristics of the iron-tin system have a large difference in the melting point, the intermetallic compound formation, and an extreme small solubility. In this paper the reaction of solid iron with molten tin was considered from the viewpoints of dissolution kinetics and metallography under an experimental condition of iron soldering. The results of this investigation may contribute to the development of improved iron soldering.

\section{Experimental Procedure}

The solid specimens used were prepared from electrolytic iron $(99.9 \%)$. The iron was vacuum-melted at $1650^{\circ} \mathrm{C}$ in a high alumina crucible, and the melt was degassed and deoxidized by the addition of preproduced $\mathrm{Fe}-\mathrm{C}$ alloy. The molten was then cast into a $10 \mathrm{~mm} \phi$ metal mould under the atmospheric pressure of argon. The deoxidized iron $(\mathrm{C}=0.06 \%)$ was coldworked to a $5 \mathrm{~mm} \phi$ rod by rolling and machined in the form of a small cylinder $2.00 \pm 0.01 \mathrm{~mm}$ in dia. and

* This paper was originally published in Japanese in $\mathrm{J}$. Japan Inst. Metals, 35 (1971), 958.

** The Research Institute for Iron, Steel and Other Metals, Tohoku University, Sendai, Japan.

(1) G. L. J. Bailey and H. C. Watkins: J. Inst. Metals, 80 $(1951 \sim 52), 57$.

(2) I. Onishi, Y. Ueda and M. Iida: J. Japan Welding Soc., 27 (1958), 220.

(3) Y. Miyazaki and R. Kawabata: J. Japan Welding Soc., Trans. JIM
$30 \mathrm{~mm}$ in length. The liquid sample used was tin of high commercial grade $(99.9 \%)$.

The experimnteal procedure is as follows. The solid specimens of cylindrical iron were immersed in liquid tin for an appropriate time and the decreases in iron cylinder diameter were measured under a static condition. From the result of the measurement, the dissolution phenomena of solid iron into molten tin were analyzed. As shown in Fig. 1, the individual tests were carried out in the hole of alumina bronze block (60 mm in dia., $110 \mathrm{~mm}$ in height) in order to obtain a homogeneous heat. The carbon crucibles $(15 \mathrm{~mm}$ in external dia., $12.0 \mathrm{~mm}$ in internal dia. and $105 \mathrm{~mm}$ in height) were charged with $45 \mathrm{~g}$ of tin weighed exactly, and heated and melted in an electrical nonmetallic resistance furnace. In order to prevent the melt from oxidizing, a flux used for

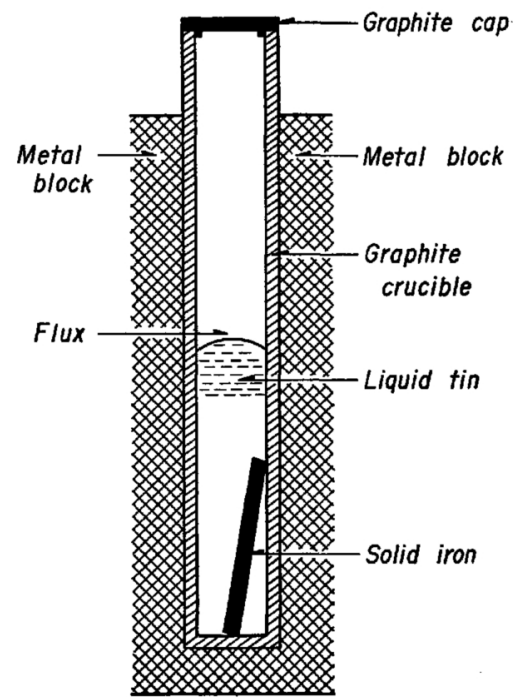

Fig. 1 Experimental apparatus.

29 (1960), 629.

(4) M. Tanaka and H. Fukunaga: J. Soc. Materials Sci., Japan, 18 (1969), 714.

(5) M. Ueda, F. Seki and K. Hosokawa: J. Japan Inst. Metals, 34 (1970), 127.

(6) T. Ishida: Sci. Rep. of Research Inst., Tohoku Univ., 22 (1970), 1.

(7) T. Ishida: Sci. Rep. of Research Inst., Tohoku Univ., 22 (1970), 18.

1973 Vol. 14 
soldering was covered with the upper of the melt. The flux composition was $71.4 \%$ zinc chloride and $10 \%$ ammonium chloride in an aqueous solution ${ }^{(8)}$. The higher the temperature, the larger became the amount of vaporization. Prior to immersion in molten tin, the individual solid specimens were scrubed with benzene and dipped in benzene. The specimens were then displaced in the flux of the same composition, heated to about $40^{\circ} \mathrm{C}$ in a beaker. As soon as the tin bathes reached the desired temperature, the solid iron specimens were withdrawn from the flux and immediately immersed into the molten tin. Temperature drop was not observed by the solid specimen immersion. The temperature was measured by immersing the $\mathrm{Pt}-\mathrm{Pt}-\mathrm{Rh}$ thermocouple into the melt. The measured temperature ranged from 445 to $780^{\circ} \mathrm{C}$. Temperatures were held within $\pm 2{ }^{\circ} \mathrm{C}$ of the desire setting. Furnace temperature was controlled by manually adjusting a variable transformer. The reaction times were $10 \sim$ $160 \mathrm{~min}$. As seen from Fig. 1, the cylindrical solid specimen was dipped slightly obliquely in the molten tin, without immersing vertically. After immersion for a certain time, the carbon crucible with the samples was rapidly cooled in the copper vessel with cooling water. The specimen was cut into the middle and the lower sections by breaking off the crucible, then polished and etched with $5 \%$ nitric acid-alcohol solution. The residual diameter was measured at a magnification of 100 times using a metallograph. In this case not a perfect circle but a little ellipsoidal shape was observed by metallography. Therefore in the measurement, the short circle was adopted as the decreasing diameter of solid iron. The measured values are the mean of the middle and lower section diameters. At the temperature below $550^{\circ} \mathrm{C}$ decrease in iron diameter was extremely small, so that the dissolved amount was presumed to be a few. Furthermore, the growth process in the alloy layer formed at the iron-tin interface was investigated by metallography in connection with the dissolution reaction. Since the migration of molten tin into solid iron was not directly observed, the migration reaction was not investigated. The diffusion rate of molten tin into solid iron appears to be extremely slow.

The iron-tin interface has an iron-alloy layer-tin boundary due to the dissolution of solid iron into molten tin. The change of the cylin drical iron specimen through the dissolution should be observed not by the change of the alloy layer but by that of iron itself. The variation in diameter measured does not involve the thickness of the alloy layer formed. Therefore the variation corresponds to the decreasing amount of iron itself. The boundary between iron and tin is flat, but that between the alloy layer and tin is irregular. Accordingly, the measurement of the diameter involving the alloy layer is not accurate.

(8) H. K. Herr: Met. Progress, 95 (1969), 68.

(9) E. A. Moelwyn-Hughes: The Kinetics of Reaction in Solution, Clarendon Press, Oxford, Second Edition, (1947), p. 374.

\section{Results and Discussion}

\section{Theory on dissolution reaction}

A most basic reaction of solid metal with liquid metal is the dissolution of solid metal into liquid metal. At the moment a solid metal contacts with a liquid metal, the dissolution of the solid into the liquid occurs. A theoretical basis for the kinetics of the dissolution of solids in liquids has been formulated from the studies of the dissolution of inorganic and organic salts in water and non-aqueous solvents ${ }^{(9)}$. Recently similar studies have been made in metal systems $^{(10) \sim(16)}$.

The over-all rate of dissolution is governed by the relative magnitudes of two separate rates, namely the rate at which atoms solvate from the solid surface into the liquid layer immediately adjacent to the solid, and the rate at which solutes diffuse from the liquid layer into the bulk of the liquid. By considering these two processes, the following relation for the rate of dissolution may be derived;

$$
n=n_{s}\left\{1-\exp \left[-\frac{K_{s}(D / \delta)}{K_{s}+D / \delta} \frac{A}{V} t\right]\right\}
$$

or

$$
\frac{d n}{d t}=\frac{K_{s}(D / \delta)}{K_{s}+D / \delta} \frac{A}{V}\left(n_{s}-n\right),
$$

where

$$
\begin{array}{cl}
n: & \text { solute concentration at time } t \\
n_{s}: & \text { saturation concentration } \\
K_{s}: & \text { interface-reaction constant } \\
D: & \text { diffusion coefficient } \\
\delta: & \text { boundary layer thickness } \\
A: & \text { solid-liquid interface area } \\
V: & \text { volume of liquid. }
\end{array}
$$

The above-mentioned relation can be indicated by the following expression;

$$
n=n_{s}\left\{1-\exp \left[-K_{\bar{V}}^{A} t\right]\right\}
$$

or

$$
\frac{d n}{d t}=K \frac{A}{V}\left(n_{s}-n\right) .
$$

Here $K$ is the dissolution-rate constant,

$$
K=\frac{K_{s}(D / \delta)}{K_{s}+D / \delta}
$$

If the dissolution process is controlled by the interface, the rate constant is given by

(10) W. D. Forgeng, Jr. and R. E. Grace: Trans. Met. Soc. AIME., 242 (1968), 1249.

(11) Z. P. Saperstein and M. A. H. Howes: Weld. J., 47 (1968), 162s.

(12) W. G. Bader: ibid., 48 (1969), 551s.

(13) E. Pelzel: Z. Metallk., 61 (1970), 289.

(14) P. K. Gairola, R. K. Tiwari and A. Ghosh: Met. Trans., 2 (1971), 2123.

(15) T. L. Sri Krishna, M. A. Dayanda and R. E. Grace: Met. Trans., 2 (1971), 3355.

(16) T. Ishida: Trans. Japan Weld. Soc., 3 (1972), 1. 


$$
K=K_{s} .
$$

On the other hand, if the dissolution process is controlled by the diffusion, the rate constant is given by

$$
K=\frac{D}{\delta} .
$$

Equation (1) or (2) has been derived assuming that the area of solid-liquid interface during dissolution is invariant. When the area is variable, it is necessary to modify the dissolution-rate equation by taking the change of the area into account. There have already been several attempts ${ }^{(17) \sim(19)}$ to derive such an equation, but the derivation method differs from each other because of the difference of the geometries in the reaction systems. An attempt was made of deriving a dissolution-rate equation for a cylindrical specimen to satisfy this experimental condition. The weight loss of the solid sample corresponds to the increment of the solute content in the liquid bulk, and there is the relation $(d n / d t)=(d n / d r) \cdot(d r / d t)$. Consequently, eq. (4) is replaced by the reducing rate of the cylinder radius $(r)$; (Detailed description has been reported previously ${ }^{(6)}$ )

$$
-\frac{d r}{d t}=K \frac{\rho_{1}}{100 \rho_{s}}\left(n_{s}-n\right)
$$

or

$$
-\frac{d r}{d t}=K\left(a+b r^{2}\right)
$$

where $a$ and $b$ are constants. Hence

$$
\begin{gathered}
a=\frac{\rho_{1} n_{s} V-100 \rho_{s} \pi h r_{0}^{2}}{100 \rho_{s} V}, \\
b=\frac{\pi h}{V},
\end{gathered}
$$

where $n_{s}$ and $n$ are denoted by weight percent, $\rho_{1}$ and $\rho_{s}$ are liquid and solid densities, and $r_{0}$ and $h$ are the initial radius and the height of a cylindrical specimen, respectively. When the solid metal dissolves and the initial mass of the cylinder is sufficient to saturate the liquid ${ }^{\dagger}$, the following kinetic equation can be obtained by integrating eq. (9):

$$
K t=\frac{1}{2 \sqrt{-a b}} \ln \frac{r_{0}-\sqrt{-\frac{a}{b}}}{r_{0}+\sqrt{-\frac{a}{b}}} \cdot \frac{r+\sqrt{-\frac{a}{b}}}{r-\sqrt{-\frac{a}{b}}}=P
$$

where the right term $P$ is referred to the dissolutionrate parameter. Equation (12) shows a dissolution-rate equation in which the variation of the solid-liquid interface area for a cylindrical specimen was considered; this equation corresponds to eq. (1).

(17) J. K. Jackson and R. E. Grace: Physical Chemistry of Process Metallurgy, Part 1, Interscience Pub., (1959), p. 633.

(18) M. Miyake, M. Iseki and T. Sano: J. Japan Inst. Metals, 29 (1965), 935.

(19) I. Kawakatsu and H. Yamaguchi: ibid., 31 (1967), 1387.

$\dagger$ The condition in which a initial mass of a solid cylinder is insufficient to saturate the liquid, that is, constant $a$ in eq. (10) is positive, has already been studied(6)(16).

\section{Dissolution of solid iron into molten tin}

The measurement of the dissolution of solid iron into molten tin had been carried out at $445,475,545$, $600,670,746$ and $780^{\circ} \mathrm{C}$. Figure 2 shows the dissolution curves of solid iron into molten tin under a static condition. The shape of the dissolution curves at high temperature differs from that at low temperature. At $600^{\circ} \mathrm{C}$ or above, the decrease in cylindrical iron diameter is relatively large at the initial dissolution time and becomes smaller with time. At temperatures below $600^{\circ} \mathrm{C}$, the decrement is small; particularly at temperatures below $500^{\circ} \mathrm{C}$, it is very small at the initial stage and tends to increase gradually with time. Therefore, in the high temperature range the rate of dissolution is relatively high at the initial stage and becomes lower with time. In the low temperature range the rate is slow; at temperatures below $500^{\circ} \mathrm{C}$ the rate is very slow at the initial stage and becomes somewhat faster with time.

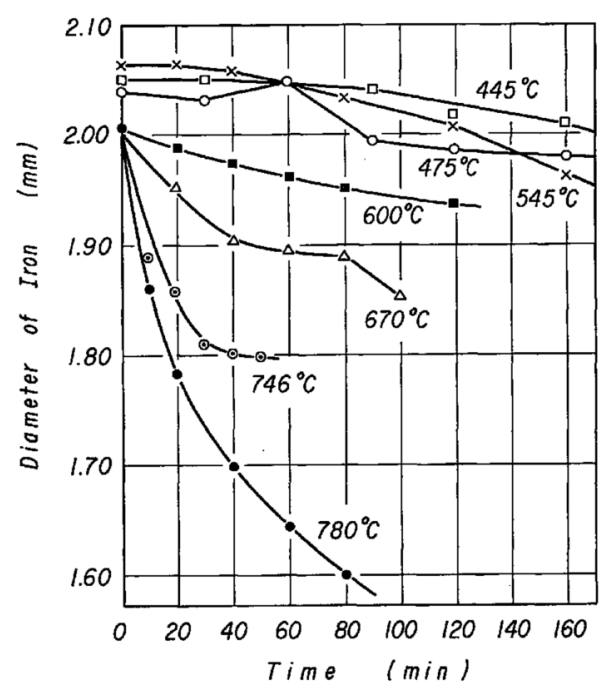

Fig. 2 Dissolution curves of solid iron into molten tin between 445 and $780^{\circ} \mathrm{C}$ under a static condition.

The values of the initial dissolution rate of solid iron into molten tin are shown in Table 1. The obtained values are small as compared with the other metallic systems measured under a static condition: For example, the value of initial dissolution rate of solid $\mathrm{Cu}$ into molten $\mathrm{Sn}^{(19)}, 7.64 \times 10^{-4} \sim$

Table 1 The values of initial dissolution rate for solid $\mathrm{Fe}$ into molten $\mathrm{Sn}$ under a static condition.

\begin{tabular}{c|c|c}
\hline $\begin{array}{c}\text { Temperatures } \\
\left({ }^{\circ} \mathrm{C}\right)\end{array}$ & $-\left(\frac{d r}{d t}\right)_{t \rightarrow 0}(\mathrm{~cm} / \mathrm{sec})$ & $v_{0}\left(\mathrm{~g} / \mathrm{cm}^{2}-\mathrm{sec}\right)$ \\
\hline 445 & $1.87 \times 10^{-7}$ & $1.43 \times 10^{-6}$ \\
475 & $3.27 \times 10^{-7}$ & $2.51 \times 10^{-6}$ \\
545 & $3.89 \times 10^{-7}$ & $2.97 \times 10^{-6}$ \\
600 & $7.50 \times 10^{-7}$ & $5.70 \times 10^{-6}$ \\
670 & $2.04 \times 10^{-6}$ & $1.54 \times 10^{-5}$ \\
746 & $8.25 \times 10^{-6}$ & $6.23 \times 10^{-5}$ \\
780 & $1.20 \times 10^{-5}$ & $9.05 \times 10^{-5}$ \\
\hline \hline
\end{tabular}


$5.06 \times 10^{-3} \mathrm{~g} / \mathrm{cm}^{2}-\mathrm{sec}\left(400 \sim 586^{\circ} \mathrm{C}\right)$, that of solid $\mathrm{Cu}$ into molten $\mathrm{Bi}^{(20)}, 2.0 \times 10^{-5} \sim 1.86 \times 10^{-4}$ $\mathrm{g} / \mathrm{cm}^{2}-\sec \left(360 \sim 510^{\circ} \mathrm{C}\right)$; that of solid $\mathrm{C}$ into molten $\mathrm{Fe}^{(21)}, 9.75 \times 10^{-5} \mathrm{~g} / \mathrm{cm}^{2}-\mathrm{sec}\left(1550^{\circ} \mathrm{C}\right)$.

The application of the rate eq. (12) has been made to the dissolution curves obtained. From the dissolution curves in Fig. 2, the diameter of the cylindrical specimen is converted into a radius of the specimen and the values of constants $a$ and $b$ are calculated under this experimental condition and using the reference data. Figure 3 shows plots of dissolution-rate parameter $P$ against reaction time $t$ in the temperature range from 600 to $780^{\circ} \mathrm{C}$. Since in the temperature range of $445 \sim 545^{\circ} \mathrm{C}$ the variation in solid-liquid interface area is ignored because of the extremely small amount of dissolution, the application to eq. (10) cannot be done. As seen from Fig. 3, the relationship between $p$ and $t$ is almost linear at $600^{\circ} \mathrm{C}$ but at temperatures higher than $670^{\circ} \mathrm{C}$ no linear relationship between them is obtained. The slope of these curves corresponds to the dissolution-rate constant $K$. The value of $K$ is constant at $600^{\circ} \mathrm{C}$, but decreases with increasing time above $670^{\circ} \mathrm{C}$. In the low temperature range, especially at temperatures below $500^{\circ} \mathrm{C}$, the value of $K$ is considered to increase with time since the rate increases gradually with time.

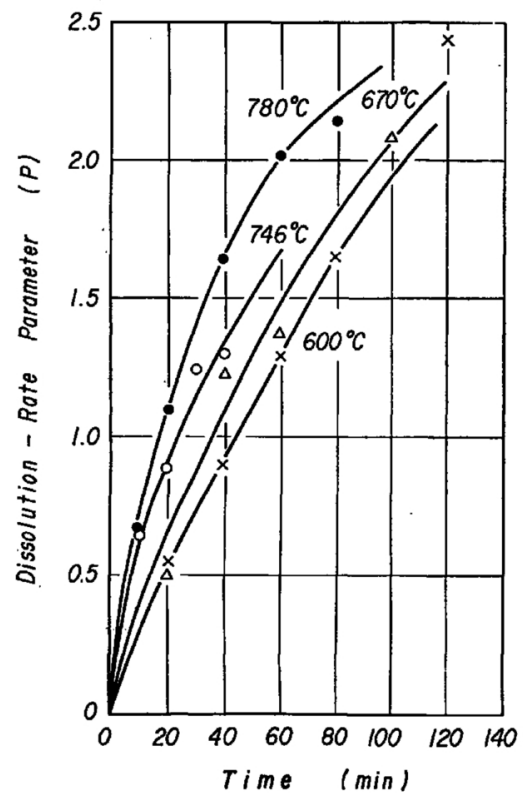

Fig. 3 Variation in dissolution-rate parameter with time for solid iron into molten tin under a static condition.

The variation in dissolution-rate constant with reaction time is due to that in the interface-reaction with time (concentration) or the diffusion coefficient or the diffusion layer thickness with time (concentration). The foregoing eq. (3) can be rewritten as follows:

$$
\ln \frac{n_{s}}{n_{s}-n}=K \frac{A}{V} t
$$

(20) A. G. Ward and J. W. Taylor: J. Inst. Metals, 85 (1956 57), 145.

(21) O. Dahlke und O. Knacke: Arch. Eisenhütt., 26 (1955), 373.
In other metal systems, a linear relationship between $\log n_{s} /\left(n_{s}-n\right)$ and $t$ is obtained ${ }^{(10)(15)(20) \sim(27)}$ and also a linear relationship between the so-called dissolution-rate parameter and time is observed. ${ }^{(17) \sim(19)(28)}$. Therefore a definite dissolutionrate constant with time is obtained on many metal systems. However, in the previous studies of the $\mathrm{Ni}-\mathrm{Pb}, \mathrm{Cu}-\mathrm{Pb}$ systems ${ }^{(29)}$, the $\mathrm{Zn}-\mathrm{Hg}$ and the $\mathrm{Ag}-\mathrm{Hg}$, $\mathrm{Sn}-\mathrm{Hg}$ systems under a stirred condition ${ }^{(30)(15)}$, a nonlinear relationship $\log n_{s} /\left(n_{s}-n\right)$ and $t$ has been shown. In these systems the dissolution-rate constant decreases with increasing time. This behaviour can be explained by the variation in diffusion coefficient or diffusion layer thickness with concentration or by the lack of interface equilibrium. The possibility that the formation of the intermediate phase exerts influence on the dissolution rate or the dissolution-rate constant is considered in the dissolution of iron into molten tin. In this experiment the dissolution proceeds with a high formation rate of the intermediate phase and a high phase growth at the same time (Photo. 1 (a) (d)) at high temperature, and proceeds gradually with a low formation rate of the intermediate phase at low temperature (Photo. 1 (e) $\sim(\mathrm{h})$ ). Hinzner and Stevenson $^{(30)}$ observed that the dissolution rate of the $\gamma$-intermediate phase (46 wt $\% \mathrm{Zn}-54 \mathrm{wt} \% \mathrm{Hg}$ ) into mercury is faster than that of pure zinc. These facts indicate that the formation of the intermediate phase does not act as a barrier for the dissolution process nor lowers the dissolution rate or the dissolution-rate constant. Therefore, at high temperature the decrease in $K$ with time is not due to the formation of an intermetallic compound, but if the rate-determining step of the dissolution is diffusion in the boundary layer of a molten metal, it should be considered to be due to the decrease in diffusion coefficient or the increase in diffusion layer thickness with solute concentration. There are data on the measurements ${ }^{(31)(32)}$ of the diffusion coefficients in the $\mathrm{Fe}-\mathrm{Sn}$ system, but the concentration dependence of the diffusion coefficients in a high-temperature range are not available. The variation in thickness of the diffusion boundary layer with concentration has not been theoretically treated

(22) M. Kosaka and S. Minowa: J. Iron and Steel Insț. Japan, 52 (1966), 1748.

(23) A. G. Ward and J. W. Taylor: J. Inst. Metals, 86 (1957 58), 36.

(24) T. Sano, M. Miyake and T. Konishi: J. Japan Inst. Metals, 24 (1960), 452.

(25) T. Sano, M. Miyake and T. Konishi: Trans. JIM, 2 (1961), 33.

(26) M. Miyake and T. Sano: J. Japan Inst. Metals, 26 (1962), 386.

(27) M. Miyake: ibid., 28 (1964), 111.

(28) J. M. Lommel and B. Chalmers: Trans. Met. Soc. AIME, 215 (1959), 499

(29) D. A. Stevenson and J. Wulff: Trans. Met. Soc. AIME, 221 (1961), 279.

(30) F. W. Hinzner and D. A. Stevenson: J. Phys. Chem., 67 (1963), 2424.

(31) C. A. Edwards and A. Preece: J. Iron Steel Inst., 124 (1931), 71.

(32) M. Kato and S. Minowa: J. Iron Steel Inst. Japan, 52 (1966), 32. 
and measured. Since at high temperature this system has a large equilibrium solubility and a liquid metal structure different from pure metal, the variation of the boundary layer will occur with a characteristic dissolution behaviour. The boundary layer is agitated by natural convection due to the density change with increase in dissolution amounts and the layer thickness is to be decreased. However, since the viscosity of liquid metal is increased with increasing solute concentration, the boundary layer thickness is also considered to be increased. The verification of these points must await experimental determination of the quantities involved.

The values of the initial dissolution-rate constant at zero time and zero solute content, $K_{m}$, and the values of activation energy for dissolution obtained from the temperature dependence of $K_{m}$ (Fig. 4) are indicated in Table 2. The obtained $K_{m}$-value increases with temperature, but at $545^{\circ} \mathrm{C}$ the value decreases and increases above the temperature. As seen from Fig. 4, the relation between $K_{m}$ and $1 / T^{\circ} \mathrm{K}$ indicates a distinct difference between the high- and low-temperature ranges, and an uniform change occurs in each temperature region. On dissolution of a solid, the liquid layer at the solid-liquid interface may rapidly reach an equilibrium state. Therefore a solid dissolution should be considered in connection with the solubility.

Table 2 The initial dissolution-rate constants and the activation energies of the dissolution for solid $\mathrm{Fe}$ into molten $\mathrm{Sn}$ under a static condition.

\begin{tabular}{c|cc}
\hline $\begin{array}{c}\text { Temperatures } \\
\left({ }^{\circ} \mathrm{G}\right)\end{array}$ & $\begin{array}{c}\text { Initial dissolution-rate } \\
\text { constants } K_{m}(\mathrm{~cm} / \mathrm{sec})\end{array}$ & $\begin{array}{c}\text { Activation energies } \\
\Delta E(\mathrm{kcal} / \mathrm{mol})\end{array}$ \\
\hline 445 & $4.88 \times 10^{-4}$ & 13.0 \\
475 & $7.35 \times 10^{-4}$ & \\
545 & $3.37 \times 10^{-4}$ & 5.64 \\
600 & $3.69 \times 10^{-4}$ & \\
670 & $4.92 \times 10^{-4}$ & 13.8 \\
746 & $7.35 \times 10^{-4}$ & \\
780 & $1.12 \times 10^{-3}$ & \\
\hline \hline
\end{tabular}

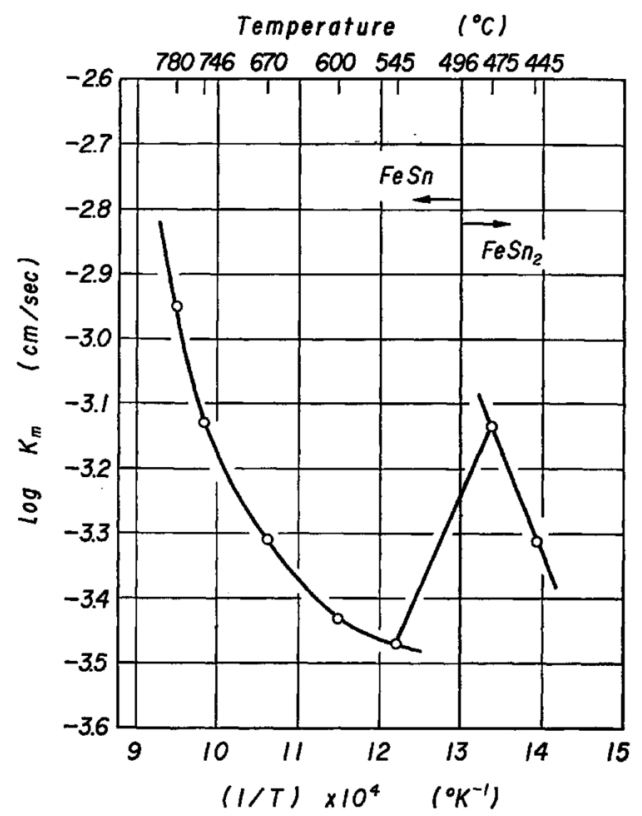

Fig. 4 Temperature dependence of initial dissolutionrate constants for solid iron into molten tin under a static condition.

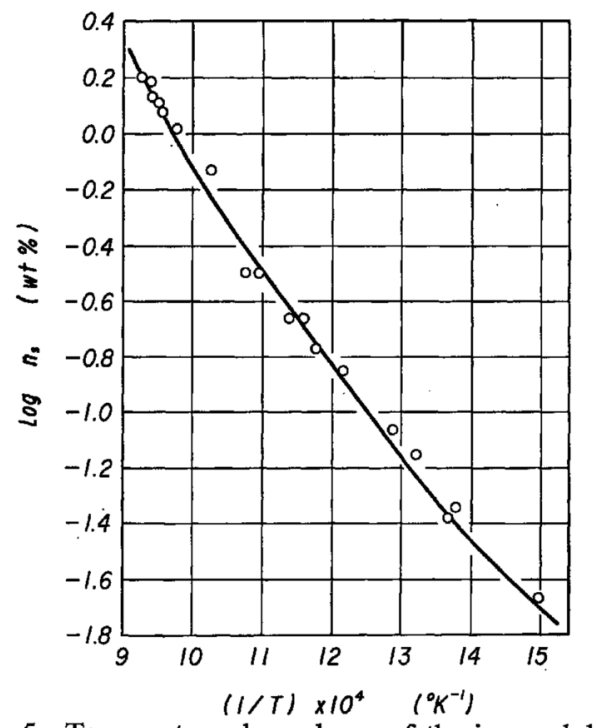

Fig. 5 Temperature dependence of the iron solubility in molten tin.

Figure 5 shows the relation between solubility $\left(n_{s}\right)$ and temperature of iron in molten $\operatorname{tin}^{(33)}$. The variation of $n_{s}$ indicates a continuous gentle curves in the highand low-temperature ranges, whereas that of $K_{m}$ shows clear discontinuity between the high- and lowtemperature ranges. Thus the difference in the dissolution behaviour between the high- and low-temperature ranges cannot be explained by the variation in solubility. According to an $\mathrm{Fe}-\mathrm{Sn}$ equilibrium diagram ${ }^{(34)}$ (Fig. 6), the intermetallic compound FeSn is formed in the high-temperature range above $496^{\circ} \mathrm{C}$, and the intermetallic compound $\mathrm{FeSn}_{2}$ in the low-temperature range below $496^{\circ} \mathrm{C}$. Consequently, by the difference in the intermetallic compound formation, the variation in the dissolution behaviour of solid iron into molten tin might occur. Thus the difference in the dissolution curves in the high- and low-temperature ranges (Fig. 2) and the discontinuity in dissolution-rate constant between the high- and low-temperature ranges are recognized.

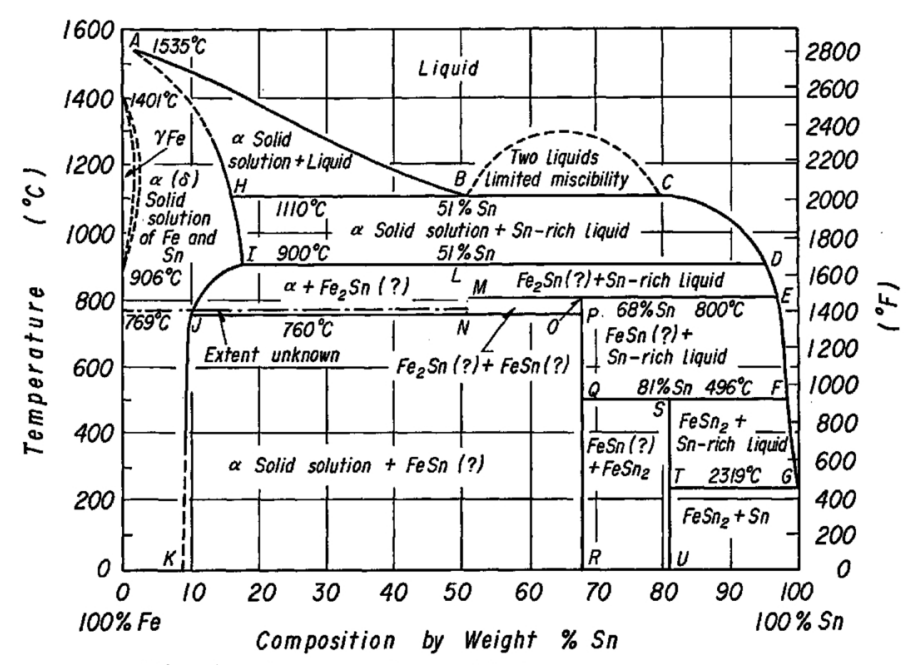

Fig. 6 The Iron-Tin equilibrium diagram (after O. E. Romig).

(33) A. N. Campbell, J. H. Wood and G. B. Skinner: J. Amer. Chem. Soc., 71 (1949), 1729.

(34) O. F. Romig: Met. Progress, 42 (1942), 899. 
The value of the activation energy for dissolution (Table 1) is relatively large at temperatures above $670^{\circ} \mathrm{C}$, decreases in the vicinity of $600^{\circ} \mathrm{C}$ and becomes large below $500^{\circ} \mathrm{C}$. The activation energy for the diffusion of solid metal into molten tin is measured as $4.2 \sim 5.2 \mathrm{kcal} / \mathrm{mol}^{(35)}$ in the range of $240 \sim 480^{\circ} \mathrm{C}$ and the value of the activation energy for the diffusion of solid iron into molten tin is $3.0 \mathrm{kcal} / \mathrm{mol}^{(32)}$ in the range of $500 \sim 900^{\circ} \mathrm{C}$. In the metal system the activation energy for dissolution has been estimated to be about $2.17 \sim 9.7 \mathrm{kcal} / \mathrm{mol}^{(19)(20)(24)(28)}$ under a static condition and the rate-determining step can be regarded as being diffusion in the boundary layer in molten metal. In this experiment all the obtained values appear to be high compared with abovementioned values, except for the value $5.64 \mathrm{kcal} / \mathrm{mol}$ in the vicinity of $600^{\circ} \mathrm{C}$.

In the case of the formation of an intermediate phase alloy layer at the solid-liquid interface, the dissolution of solid metal consists of the four processes of alloy layer formation, growth (diffusion in the alloy layer), interface reaction from the layer into liquid metal and diffusion in liquid bulk. The formation of intermetallic compound in the Fe-Sn system is complicating the dissolution process, as is discussed below.

In the high-temperature range above $496^{\circ} \mathrm{C}$, the rate of alloy layer formation is very rapid (Photo. 1 (a)), and at the same time the dissolution proceeds with the growth of the alloy layer (Photo. 1 (a) $\sim$ (d)). If the diffusion rate in the alloy layer is comparable to that in the solid metal, the rate-determining step in the dissolution process is diffusion in the alloy layer. No detailed study has been reported on the diffusion in the alloy layer in the $\mathrm{Fe}-\mathrm{Sn}$ system. There are some reports on the other systems such as $\mathrm{Fe}-\mathrm{Al}^{(36) \sim(38)}, \mathrm{Cu}-$ $\mathrm{Sn}^{(19)(39)}$ and $\mathrm{Cu}-\mathrm{Zn}^{(40)}$. The diffusion rate in the alloy layer of these systems seems to be relatively high. Heumann et al. indicated that the intermetallic compound has anisotropic diffusion in the direction of the c-axis of the $\eta$-phase $\left(\mathrm{Al}_{2} \mathrm{~F}_{5}\right)$ and the activation energy of the diffusion process is $13.1 \mathrm{kcal}$ per g-atomic weight. Kawakatsu et al. also demonstrated that the thickness of the alloy layer increases in proportion to the reaction time and the diffusion rate in the alloy layer is very fast. In this experiment, too, the development of the alloy layer is observed to be relatively fast (the detailed discussed below) and the dissolution proceeds with the growth of the alloy layer. Therefore the rate-determining step in the dissolution is considered not to be diffusion in the alloy layer. There is no evidence supporting that the diffusion rate in the

(35) C. H. Ma and R. A. Swalin: Acta Met., 8 (1960), 388.

(36) T. Heumann and S. Ditrich: Z. Metallk., 50 (1959), 617.

(37) S. Koda, S. Morozumi and A. Kanai: J. Japan Inst. Metals, 26 (1961), 764.

(38) S. Minowa and M. Kosaka: J. Iron and Steel Inst. Japan, 50 (1964), 56.

(39) I. Kawakatsu, T. Osawa and H. Yamaguchi: J. Japan Inst. Metals, 34 (1970), 539.

(40) T. Heumann and A. Kottmann: Z. Metallk., 44 (1953), 139. alloy layer is fast on the dissolution in the $\mathrm{Fe}-\mathrm{Sn}$ system. However, the high vacancy concentration in the alloy layer and the formation of texture should make the diffusion rate faster. Thus in the high-temperature range above $496^{\circ} \mathrm{C}$, the dissolution depends on the reaction between the alloy layer and molten tin. Since the value of activation energy for dissolution at a temperature in the vicinity of $600^{\circ} \mathrm{C}$ is in approximate agreement with that for diffusion of iron into molten tin, the rate-determining step in the dissolution is considered to be diffusion in the boundary layer of liquid tin. At high temperatures above $670^{\circ} \mathrm{C}$ a relatively large value of the activation energy of tenth order $\mathrm{kcal} / \mathrm{mol}$ is obtained. At low temperatures the variation of boundary layer thickness with temperature does not occur, but in the high temperature range it is impossible to consider a constant boundary layer thickness. In the high-temperature range where the dissolution amount increases, the convection effect due to the density variation makes the boundary layer turbulent and brings about the decrease in the so-called effective boundary layer thickness. Thus a large dissolution-rate constant given by $D / \delta$ and a large activation energy for dissolution are obtained. Such a behaviour has been observed for the dissolution of solid $\mathrm{Ni}, \mathrm{Ag}$ and $\mathrm{Cu}$ into molten $\mathrm{Bi}^{(26)}$. Therefore the variation of dissolution behaviour in the high-temperature range occurs with decreasing thickness of the boundary layer immediately adjacent to the alloy layer in liquid metal. In this case the rate-determining step in the dissolution is the diffusion in the boundary layer of liquid metal immediately adjacent to the alloy layer.

In the low temperature range below $496^{\circ} \mathrm{C}$, the rate of the alloy layer formation is very slow (Photo. 1 (e)) and the dissolution proceeds gradually with the formation and growth of the layer (Photo. 1 (f)). The value of the activation energy for the formation of $\mathrm{FeSn}_{2}$ has been measured as $14.3 \mathrm{kcal} / \mathrm{mol}^{(41)}$. The value of activation energy for the dissolution in the low-temperature range is comparable to the value reported on the activation energy for the formation of $\mathrm{FeSn}_{2}$. Therefore, in the low-temperature range below $496^{\circ} \mathrm{C}$ the rate-determining step is the formation of the alloy layer. From the fact that the dissolution proceeds with the development of the alloy layer with time, the rate-determining step is considered to change into a reaction between the alloy layer and molten tin. However, it is uncertain whether the rate of dissolution is controlled by diffusion in the molten tin.

\section{The metallographic examination of iron-tin interface}

Photograph 1 shows solidified structures of the $\mathrm{Fe}-$ $\mathrm{Sn}$ interfaces through the dissolution of solid $\mathrm{Fe}$ into molten Sn. In these interfaces, the intermetallic compound FeSn is formed at high temperature, and the intermetallic compound $\mathrm{FeSn}_{2}$ at low temperature $^{(42)(43)}$. These intermetallic compounds grow with time. At high temperatures the alloy layer of the intermetallic compound grows at a relatively faster rate with reaction time (Photo. 1 (a) $\sim($ d)). At low 


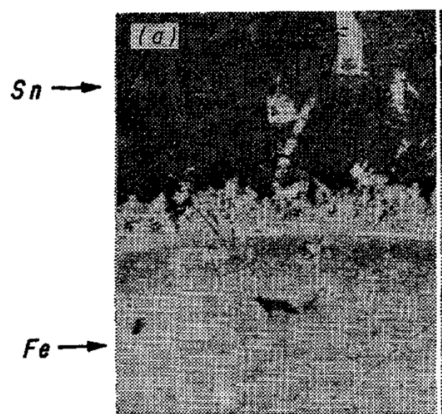

(a) $10 \mathrm{~min}$

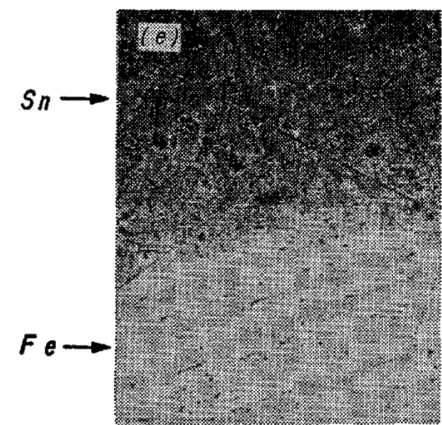

(e) $30 \mathrm{~min}$

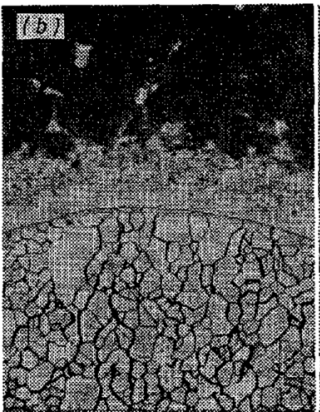

(b) $20 \mathrm{~min}$

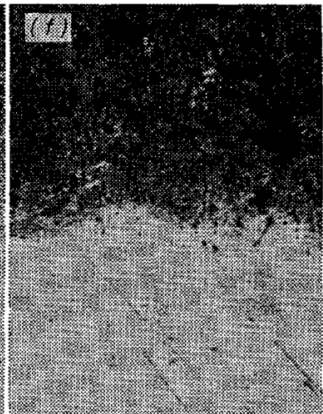

(f) $60 \mathrm{~min}$

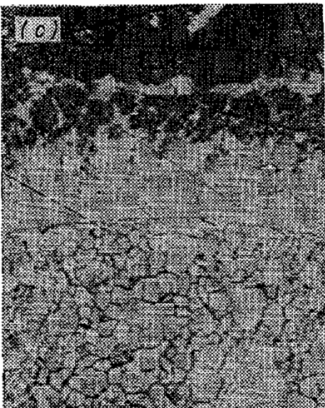

(c) $40 \mathrm{~min}$

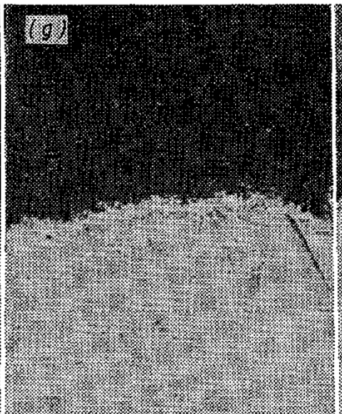

(g) $90 \mathrm{~min}$

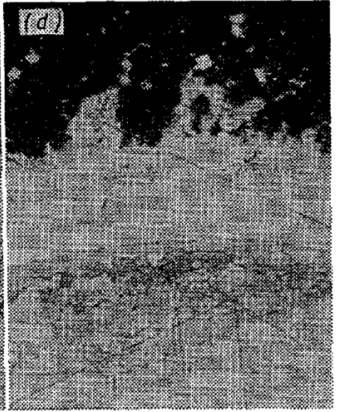

(d) $60 \mathrm{~min}$

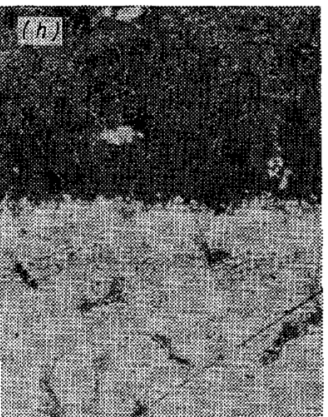

(h) $120 \mathrm{~min}$

Photo. 1 Microstructures of the solidified iron-tin interface $(\times 100 \times 2 / 3$, Etchant: $5 \%$ Nital $)$ (a) $\sim$ (d), reacted at $780^{\circ} \mathrm{C} \quad\left(\right.$ e) $\sim(\mathrm{h})$, reacted at $445^{\circ} \mathrm{C}$

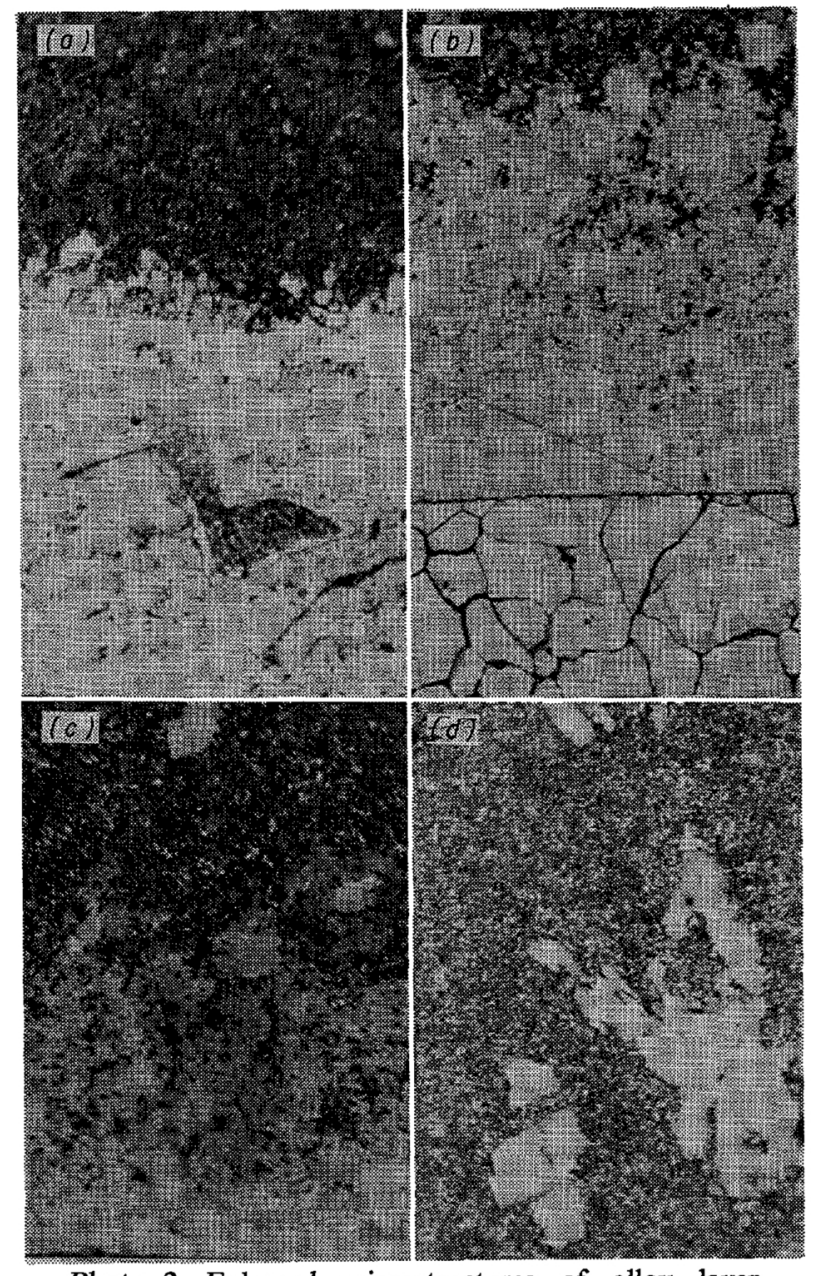

Photo. 2 Enlarged microstructures of alloy layer formed at the iron-tin interface and intermetallic compound crystallized within the tin $(\times 400 \times 2 / 3$, Etchant: $5 \%$ Nital $)$

(a) Iron-tin interface $\left(445^{\circ} \mathrm{C}, 120 \mathrm{~min}\right)$

(b) Iron-tin interface $\left(780^{\circ} \mathrm{C}, 40 \mathrm{~min}\right)$

(c) Alloy layer-tin interface $\left(780^{\circ} \mathrm{C}, 20 \mathrm{~min}\right)$

(d) Intermetallic compounds crystallized within the tin $\left(670^{\circ} \mathrm{C}, 20 \mathrm{~min}\right)$ temperatures the formation rate of the alloy layer is extremely slow (Photo. 1 (e)) and the growth of the alloy layer occurs with the formation (Photo. 1 (g), (h)). In order to clarify the formation state of the alloy layer, their enlarged photomicrographs are shown in Photo. 2 (a) $\sim$ (c). In the high temperature range a boundary between iron and the alloy layer is even (Photo. 1 (a) (d), Photo. 2 (b), (c)), but in the low temperature range the boundary is observed to be irregular. With the growth of the alloy layer, the boundary between alloy layer and tin is also observed to be disturbed (Photo. 1 (e), (f), Photo. 2 (a)) in a way similar to that in the high temperature range. These facts lead to the conclusion that at high temperatures the dissolution depends largely on the reaction between the alloy layer and molten tin, and that at low temperatures the dissolution is governed by the reaction between solid iron and molten tin in the stage of the early reaction and the dissolution process is changed into the reaction between the alloy layer and molten tin with time. The dissolution of solid iron into molten tin proceeds with an intensive reaction between molten tin and the alloy layer which is growing at the solidliquid interface. It is clear that the formation rate of the alloy layer is not consistent with the dissolution rate. As seen from Photo. 2 (d), the intermetallic compounds are crystallized within the tin through such a dissolution.

\section{Conclusions}

A basic study of soldering in iron has been made of the reaction between solid iron and molten tin from

(41) A. U. Seybolt: Trans. ASM, 29 (1941), 937.

(42) J. E. Davies and W. E. Hoare: J. Iron Steel Inst., 168 (1951), 134.

(43) C. I. Thwaites: J. Iron Steel Inst., 159 (1956), 244. 
the viewpoints of dissolution kinetics and metallography. The results obtained are as follows:

(1) The rate of the dissolution of solid iron into molten tin is relatively slow and the value of the initial dissolution rate is $1.43 \times 10^{-6} \sim 9.05 \times 10^{-5}$ $\mathrm{g} / \mathrm{cm}^{2}$-sec in the temperature range of $445 \sim 780^{\circ} \mathrm{C}$ under a static condition.

(2) By integrating the reducing rate equation of the radius of cylindrical solid specimens in which the variation of the solid-liquid interface area was considered, eq. (12) was obtained and its application has been done. The value of the initial dissolution-rate constant is $3.37 \times 10^{-4} \sim 1.12 \times 10^{-3} \mathrm{~cm} / \mathrm{sec}$ and the activation energy for dissolution varies with the temperature.

(3) By the formation of intermetallic compound $\mathrm{FeSn}$ at high temperature and $\mathrm{FeSn}_{2}$ at low temperature, the dissolution mechanism in the high-temperature range above $496^{\circ} \mathrm{C}$ differs from that in the lowtemperature range below $496^{\circ} \mathrm{C}$. The formation of the intermetallic compound does not act as a dissolution reaction barrier.

(4) The rate-determining step in the dissolution is diffusion across the effective boundary layer of molten metal immediately adjacent to the alloy layer in the high-temperature range. In the low-temperature range the step is the formation of intermetallic compound in the early stage of the reaction, but it changes into the reaction between the alloy layer and molten metal with the elapse of reaction time.

(5) The dissolution of solid iron into molten tin proceeds with an intensive reaction between molten tin and the alloy layer which is growing at a relatively rapid rate at the solid-liquid interface.

\section{Acknowledgement}

The author is grateful to Professor M. Homma of the Research Institute for Iron, Steel and Other Metals, Tohoku University, for his valuable advice and encouragement. 